IZA DP No. 9973

Disentangling the Wage Impacts of Offshoring on a Developing Country: Theory and Policy

Subhayu Bandyopadhyay

Arnab K. Basu

Nancy H. Chau

Devashish Mitra

May 2016 


\title{
Disentangling the Wage Impacts of Offshoring on a Developing Country: Theory and Policy
}

\author{
Subhayu Bandyopadhyay \\ Federal Reserve Bank of St. Louis and IZA
}

Arnab K. Basu

Cornell University and IZA

Nancy H. Chau

Cornell University and IZA

Devashish Mitra

Syracuse University and IZA

Discussion Paper No. 9973
May 2016

IZA

P.O. Box 7240

53072 Bonn

Germany

Phone: +49-228-3894-0

Fax: +49-228-3894-180

E-mail: iza@iza.org

Any opinions expressed here are those of the author(s) and not those of IZA. Research published in this series may include views on policy, but the institute itself takes no institutional policy positions. The IZA research network is committed to the IZA Guiding Principles of Research Integrity.

The Institute for the Study of Labor (IZA) in Bonn is a local and virtual international research center and a place of communication between science, politics and business. IZA is an independent nonprofit organization supported by Deutsche Post Foundation. The center is associated with the University of Bonn and offers a stimulating research environment through its international network, workshops and conferences, data service, project support, research visits and doctoral program. IZA engages in (i) original and internationally competitive research in all fields of labor economics, (ii) development of policy concepts, and (iii) dissemination of research results and concepts to the interested public.

IZA Discussion Papers often represent preliminary work and are circulated to encourage discussion. Citation of such a paper should account for its provisional character. A revised version may be available directly from the author. 
IZA Discussion Paper No. 9973

May 2016

\section{ABSTRACT \\ Disentangling the Wage Impacts of Offshoring on a Developing Country: Theory and Policy}

The various channels through which a reduction in the cost of offshoring can improve wages in a developed country are by now well understood. But does a similar reduction in the offshoring cost also benefit workers in the world's factories in developing countries? Using a parsimonious two-country model of offshoring we find very nuanced results. These include cases where wages monotonically improve or worsen as well as those where wages exhibit an inverted $U$-shaped relationship in response to parametric reductions in the cost of offshoring. We identify qualitative conditions under which wages and welfare increase or decrease in the developing world as a result of a reduction in offshoring costs. Since global welfare always rises with an improvement in offshoring technology, we find that there is a role for a wage tax or a minimum wage in the developing country. We derive the optimal levels of such policies.

JEL Classification: F11, F13, F16, F66, O19, O24

Keywords: wages, international offshoring, wage tax, minimum wage

Corresponding author:

Nancy H. Chau

Charles H. Dyson School of Applied Economics and Management

Cornell University

Ithaca, NY 14853

USA

E-mail: hyc3@cornell.edu

\footnotetext{
* We thank seminar participants at the Midwest International Trade Conference, the IIPF Conference, the ISI-D Growth and Development Conference, and the Federal Reserve System Applied Microeconomics Conference for useful comments and suggestions.

Any opinions, findings, and conclusions or recommendations are solely those of the authors and do not necessarily reflect the view of the Federal Reserve Bank of St. Louis or of the Federal Reserve System.
} 


\section{Introduction}

In this paper, we study the impact of a reduction in the costs of the offshoring of production tasks from a developed to a developing country on the latter's wage and welfare. We also derive optimal economic policies in the developing country that ensure that it gets a share of the global welfare gains arising from these reductions in offshoring costs, which might not be the case in the absence of these policies. Since offshoring costs directly affect the demand for labor in the offshoring sector, our optimal policy prescriptions mainly consist of labor market policies, such as a wage tax or minimum wage, specific to that sector.

We build here on the pioneering work of Grossman and Rossi-Hansberg (2008), GRH from now on. GRH present a simple but insightful two-sector, two-factor model of offshoring, where offshoring takes the form of "trade in tasks." In that model the range of tasks (of unskilled labor) offshored from the developed to the developing world expands as there is a general equiproportional decline in the cost of offshoring of all tasks (which from now on we will call a parametric reduction or simply a reduction in offshoring costs). This expansion of the range takes place by bringing more and more complex tasks into the fold of offshoring. Yet these tasks are less complex than those that stay in the developed country. GRH's focus is on the impact of a parametric reduction in the cost of offshoring on wages in the developed world, with the host (developing)

country wage taken as exogenously given. They find a positive "productivity effect" on developed country unskilled wage of such an offshoring cost reduction. While this is the only effect in a developed country that is small in the market for final goods, in a large developed country there are additional offsetting effects from cost savings (leading to a lower relative price of the unskilled labor intensive good) and the effective labor supply increase (due to the labor released as a result of greater offshoring).

We build a two-country (developed and developing), two-sector model, with constant returns to labor (performing a continuum of tasks in the GRH fashion) in one sector 
and a diminishing-returns-to-labor production function in the other sector. ${ }^{1}$ Following GRH, our main comparative static exercise will be a parametric reduction in the cost of offshoring. Unlike GRH, however, we will fully model the developing country's labor market and study how this market responds to such an offshoring cost reduction. Therefore, what this offshoring cost reduction means needs to be clearly understood right at the outset.

In the words of Hummels, Munch and Xiang (2016), "Offshoring costs here could reflect costs of trade such as tariffs or shipping or it could represent the difficulty of managing and integrating particular activities from a distance." With the trade costs interpretation, with these costs taking the iceberg form, for a unit of the input to reach the developed country from the developing country more than a unit will have to be produced and shipped. A reduction in this cost will, therefore, lead to a reduction in the developing country's labor requirement per unit of task or input reaching the destination, namely the developed country. Alternatively, with the other interpretation, an offshoring cost reduction means that managing and integrating activities performed abroad becomes easier. As a result, developing country labor will become more productive in these offshored tasks due to better supervision and monitoring from the developed country and the unit labor requirement once again will fall. A third interpretation could be greater automation, which also reduces the unit labor requirement directly or indirectly through lower wastage arising from a smaller proportion of defective pieces of inputs produced.

For a constant range of tasks offshored and for given employment in the offshoring sector in the developed country, less developing country labor is demanded in these tasks when there is a parametric reduction in offshoring costs. On the other hand, a larger range of tasks offshored, as a result of this offshoring cost decline, is a labor demand increasing force. Whether labor demand goes up or down (and whether, in turn, there is upward or downward pressure on the wage) in the developing country as a result

\footnotetext{
${ }^{1}$ The diminishing returns to labor can be a consequence of the existence of a sector-specific factor in the background.
} 
of the net effect of these two opposing forces will depend on the responsiveness of the proportion of tasks offshored to reductions in the offshoring cost. There is, however, also a positive "productivity effect" which has a wage increasing effect. Nevertheless, an overall negative impact of an offshoring cost reduction on the developing country wage is a real possibility, as shown by our simulations for various parameter values. We also derive conditions analytically for this possibility as well as for the opposite outcome. Our simulations show cases where wages monotonically improve or worsen as well as those where wages exhibit an inverted U-shaped relationship in response to parametric reductions in the cost of offshoring. The wage in the developed country always increases with a decline in the offshoring cost.

It is important to note that the equilibrium aggregate welfare in each of the countries in our model is monotonically increasing in its equilibrium wage, which means there is the possibility that developing country welfare falls with a reduction in offshoring costs. However, we find that there will always be an increase in global welfare (joint welfare of developed country and the developing country) when offshoring costs go down. As a result, there is a role for policy in the developing country to make sure the citizens there get a share of these global welfare gains. As the offshoring decisions in the developed country directly affect labor demand in the sector where workers work on the offshored tasks (offshoring sector from now on), the policies we look at directly target workers in that sector. ${ }^{2}$ In particular, we analyze the effects of a sector-specific wage tax and minimum wage policy in the developing nation. We also derive optimal levels of these policies.

Since the developing country has monopoly power as a seller of labor services in tasks to the developed country, like any monopolist the developing country can gain by

\footnotetext{
${ }^{2}$ One may argue that offshoring is a type of trade and that, therefore, the government is trying to fix a directly trade related distortion, for which the first-best line of attack is trade policy. In this case, such a policy should be an export tax (or by Lerner symmetry an import tariff). However, note that the export here is of labor services in tasks offshored. Since these services are not directly consumed in the developing country and are exclusively produced for export, viewing workers in the offshoring sector as exporters of these services, we can see that there is no difference effectively between an export tax and a wage tax. However, using trade policy disguised in the form of a wage tax or a minimum wage (rather than directly) might be less objectionable to trading partners.
} 
restricting the supply of what it is selling, in this case labor services in the production of tasks. This is done through either a wage tax or a minimum wage in that sector. Such restrictions move the terms of trade of the developing country in its favor, i.e., increase the wage paid (gross of tax) to the country's workers in the offshoring sector. ${ }^{3}$ While the labor allocation and welfare effects of the two policies are the same, there are pros and cons of the two alternatives. With a wage tax, the net wage is equal between the sectors and the tax receipts are equally distributed on a per head basis - this means that all labor heads get equal income. With a sector-specific minimum wage, wages differ between the sectors (and there are no tax revenues). Thus, a higher minimum wage results in a higher inequality between workers in the two sectors. However, a discriminatory tax on workers in a particular sector might face resistance and could be unpopular. There might be greater "obfuscation" with the minimum wage on this issue and, as a result, it might not face as much resistance. For example, here one can say that the developing country government is preventing the multinationals from paying a standard, low developing country wage or is making them pay a higher wage, especially because multinationals pay a much higher wage in their home country. It is relevant here that Harrison and Scorse (2008) find evidence from Indonesia that there is stricter compliance of minimum wage and other labor standards by foreign firms relative to domestic firms as the former are more focused targets of activism by labor advocacy groups and anti-sweatshop campaigns. Thus, at least effectively, there exists a sector-specific minimum wage. ${ }^{4}$

We find that the welfare-maximizing sector-specific wage tax rate or alternatively the wedge between the wages in the offshoring sector and the other sector created by the minimum wage (specific to the offshoring sector) is inversely related to the total wage elasticity of the demand for labor in the developing country created by the tasks offshored to that country. Furthermore, in the presence of such an optimal wage tax or minimum

\footnotetext{
${ }^{3}$ We assume that the developed country government is passive in that it does not try to formulate policies to move the terms of trade towards itself. We believe this is a reasonable assumption, given that no developed country would like to be seen as coming in the way of any developing country's attempts towards moving to a higher real income through its own domestic labor-market policies.

${ }^{4}$ See also Krautheim and Verdier (2015) who look at the endogenous emergence of NGO activism in the presence of offshoring that makes it costly for multinational firms to implement dirty technology that hurt consumers at home.
} 
wage that adjusts to changes in the offshoring costs, a parametric reduction in the offshoring cost will always lead to a welfare gain for the developing country. Also, except with extremely convex labor demand functions, this optimal wage tax (or alternatively, the optimal sector-specific minimum wage) rises as the cost of offshoring falls. We also briefly discuss the less efficient policy of an optimal general minimum wage.

The policy implications discussed above have relevance as long as a host country has enough monopoly power in the market for tasks. In manufacturing, China has a lion's share of all the world's input processing while India is a major destination of service offshoring, especially in information technology and information technology enabled services. These countries, therefore, have considerable market power in the markets for "tasks." However, as they specialize in tasks offshored in different sectors (manufacturing in China and services in India) due to differences in infrastructure and skills available, they are not viewed as substitute countries, making our analysis relevant.

The new literature on offshoring pioneered by GRH has focused policy attention on the effects of offshoring on labor-market effects in developed nations. The literature has established that, contrary to popular belief, laborers in developed nations can benefit from offshoring. The empirical literature has established that offshoring and developed nations' employment can be complements rather than substitutes. For example, Desai et al. (2005) show a strong positive correlation between foreign activities and domestic activities of US multinational firms. Mankiw and Swagel (2006) conclude that increased employment in the overseas affiliates of U.S. multinationals is associated with more employment in the U.S. parent. Harrison and McMillan (2011) find that foreign employment and domestic employment are substitutes for firms undertaking horizontal foreign direct investment and they are complements for firms undertaking vertical foreign direct investment. Most of the remaining recent related theoretical literature also focuses on the impact on the developed world. ${ }^{5}$ There has also been some important work on two-way

\footnotetext{
${ }^{5}$ For example, in line with the theoretical results in GRH discussed above, Mitra and Ranjan (2010) show that offshoring from a developed to a developing country may reduce the developed country's equilibrium search unemployment. See also Ranjan (2013) for how the impact of offshoring on unemployment depends on the nature of labor market institutions (collective bargaining versus individual bargaining) but again has a developed country focus (for example, US versus Euope). For an in-depth survey of the
} 
offshoring between similar countries. ${ }^{6}$

On the impact of offshoring on developing countries, there is recent work by Bergin, Feenstra and Hanson (2011). This paper is related to ours in that it also shows a channel through which offshoring from a developed to a developing country can have an adverse effect on the latter but, differently from ours, this effect works through the export of volality from the former to latter. ${ }^{7}$ There is also the earlier influential work by Feenstra and Hanson $(1996,1997)$ which looks at the impact of offshoring of tasks (or inputs) that vary by skill intensity from a developed to a developing country. While they look at the impact on both the developed as well as the developing country their main variable of interest is wage inequality (the ratio of the skilled to unskilled wage). They try to explain their empirical finding of rising wage inequality in developed as well as developing countries. $^{8}$

There is an older literature that looks at the impact of offshoring in the form of vertical foreign direct investment (FDI) on developing country labor markets. One example of such a paper on vertical FDI is Helpman (1984), in which unskilled wage can go up in developing countries as a result of such FDI. While many empirical and earlier theoretical papers on vertical FDI arrive at the conclusion that vertical FDI has positive effects on developing country labor markets (McMillan, 2009), unlike our paper they do not look at the impact of small and gradual reductions in offshoring costs (fall in trade costs, easier overseas supervision and monitoring and greater automation) that bring in more and more complex tasks into the fold of offshoring. We view the earlier theoretical

literature on offshoring and labor markets, see Hummels, Munch and Xiang (2016).

${ }^{6}$ For example, Grossman and Rossi-Hansberg (2012) focus on "trade in tasks" between two similar countries, with an economies-of-scale element embedded in the model. Another important paper looking at two-way offshoring between similar countries is Burstein and Vogel (2010) where a number of tradable inputs are used to produce one nontradable final good and where input-specific productivities are random draws from a common distribution along the lines of Eaton and Kortum.

${ }^{7}$ Wage increases in the developed country during upswings of the business cycle will result in increases in offshoring to the developing country, while during downswings offshoring will go down. Thus offshoring stabilizes the wage in the developed country but increase its volatility in the developing country.

${ }^{8}$ They show that offshoring can shift the least skill-intensive tasks from a developed country to a developing country and yet these tasks could end up being among the most skill-intensive of all tasks in the latter. Thus, the relative demand for skilled labor goes up in both developed and developing countries, resulting in a rise in wage inequality. 
literature, that does not have a task-trade view of offshoring but focuses on vertical FDI, and our work as complementary in the understanding of the impact of offshoring on developing country labor markets.

Thus the focus of the recent literature on offshoring modeled as trade in tasks is predominantly on the developed nations' labor markets. The developing nations' markets are typically black-boxed by assuming that they supply labor at constant terms-of-trade. It is, however, important to explore how such offshoring may impact developing nations. While this focus is important by itself, it also informs us about the feedback effects on developed nations.

\section{A Parsimonious Two-Country Model of Offshoring}

Consider a world where there is a developed nation and a developing nation. The developed nation allocates her workers between two sectors, $x^{*}$ and $y^{*}$. Both the developed and developing nations are small open economies who take prices $p_{x}, p_{y}$ as given. Henceforth, we take $y$ as the numeraire and set $p_{y}=1$. The production technology in $y^{*}$ uses labor only, $F_{y}^{*}\left(L_{y}^{*}\right)$, and exhibits strictly diminishing marginal returns. ${ }^{9}$ Let the derived labor demand in $y^{*}$ given $w^{*}$ be $L_{y}^{*}\left(w^{*}\right)=\left\{L_{y}^{*} \mid \partial F_{y}^{*}\left(L_{y}^{*}\right) / \partial L_{y}^{*}=w^{*}\right\}$. In $x^{*}$, tasks can be performed domestically, in the developing country, or both. Along the lines of GRH, a unit of $x^{*}$ requires a continuum of labor tasks $i \in[0,1]$ to be performed. Total labor supply of the developed nation is inelastically given at $\bar{L}^{*}$. The economy-wide wage rate in the developed nation is fully flexible and competitively determined, $w^{*}$.

The developing nation $H$ likewise allocates workers between two sectors $y$ and $x$. Production technology in $y, F_{y}\left(L_{y}\right)$, exhibits strictly diminishing marginal returns. As in the developed nation, let derived labor demand in $y$ given $w$ be $L_{y}(w)=\left\{L_{y} \mid \partial F_{y}\left(L_{y}\right) / \partial L_{y}=\right.$ $w\}$. Workers in the $x$ sector perform tasks offshored from the developed nation. There are $\bar{L}$ total number of workers here, and wages in the two sectors are flexibly and competitively determined, $w$.

In the standard labor market representation, we denote $i$ as the complexity of a

\footnotetext{
${ }^{9}$ Diminishing returns here can be a consequence of a fixed or specific factor in the background.
} 
task. Offshoring a task $i$ from the developed to the developing nation requires a cost of $\beta t(i)$ of the developing nation's labor [where $\beta>0$ and $t(i)>1$ for all $i] .{ }^{10}$ Assume henceforth that $t(i)$ is monotonically increasing in $i$ so that the offshoring cost is increasing in the complexity of the task. Furthermore, let any task $i$ require $a^{*}$ units of labor to complete in the developed nation and $a$ units of labor to complete in $H$. For simplicity let $a^{*}=a=1$. Therefore, a task $i$ is offshored to $H$ if and only if:

$$
w^{*} \geq w \beta t(i)
$$

Or,

$$
t(i) \leq \frac{w^{*}}{w \beta} .
$$

Define $I=\left\{I \mid t(I)=w^{*} /(w \beta)\right\}$. By monotonicity of $t(i)$, it is clear that tasks $i \in(I, 1]$ cost more to be done in the developing nation, and hence are conducted in the developed nation. The remaining tasks $i \in[0, I]$ are offshored to the developing nation. Thus, total employment in $x^{*}$ is simply $L_{x}^{*}=x^{*}(1-I)$, while total employment in $x$ is given by $L_{x}=x^{*} \beta \int_{0}^{I} t(i) d i$. The employment ratio of tasks conducted in the developing country relative to tasks conducted in the developed country is:

$$
\lambda=\frac{L_{x}}{L_{x}^{*}}=\frac{\beta \int_{0}^{I} t(i) d i}{1-I} .
$$

Henceforth we shall refer to $\lambda$ the offshored employment intensity of sector $x$. As shown, this intensity depends only on the marginal task offshored $I$, or equivalently, the relative wage cost, $w^{*} /(w \beta)$, for $I=\left\{i \mid t(i)=w^{*} /(w \beta)\right\}$. Henceforth, denote the relative wage cost

$$
\frac{w^{*}}{w \beta} \equiv \rho
$$

Since $\lambda$ is increasing in the complexity of the marginal task $I$, the offshored employment intensity $\lambda$ is thus strictly increasing in the relative wage cost $\rho$. Henceforth, let $\epsilon$ denote

\footnotetext{
${ }^{10}$ In the rest of the paper we refer to a reduction of $\beta$ as an improvement in offshoring technology, or as a parametric reduction in offshoring cost. It is important to note that offshoring cost also involves endogenous elements like the range of tasks offshored and the wage rates at which such tasks are performed. Hence, when we write "parametric reduction in offshoring cost", we are referring solely to the exogenous element of the cost, captured by $\beta$.
} 
the elasticity of the efficiency adjusted offshored employment intensity with respect to $\rho$ : $\epsilon=d \log (\lambda / \beta) / d \log (\rho)$

Full employment in the developed and developing nations requires that:

$$
\begin{aligned}
\bar{L}^{*} & =L_{y}^{*}\left(w^{*}\right)+L_{x}^{*}=L_{y}^{*}\left(w^{*}\right)+x^{*}(1-I), \\
\bar{L} & =L_{y}(w)+L_{x}=L_{y}(w)+x^{*} \beta \int_{0}^{I} t(i) d i .
\end{aligned}
$$

Using (2), the full employment conditions in the two countries can be succinctly summarized as follows:

$$
\lambda L^{*}\left(w^{*}\right)=L(w)
$$

where $L^{*}\left(w^{*}\right) \equiv \overline{L^{*}}-L_{y}^{*}\left(w^{*}\right)$ denotes the effective labor supply to $x^{*}$ in the developed nation and $L(w) \equiv \bar{L}-L_{y}(w)$ denotes the effective labor supply to $x$ in the developing nation. Henceforth, let $\eta^{*}$ and $\eta$, both positive, respectively denote the elasticity of $L^{*}\left(w^{*}\right)$ and $L(w)$.

Henceforth, denote $\mathrm{a}^{\wedge}$ as proportionate change $(\hat{x}=d x / x)$. Equation $(3)$ gives

$$
\left(\eta^{*}+\epsilon\right) \hat{w}^{*}-(\eta+\epsilon) \hat{w}=(\epsilon-1) \hat{\beta}
$$

(4) defines a global labor market equilibrium. In Figure 1, this is denoted as schedule L. From (4), we note that factors that tighten the developed country labor market by raising $w^{*}$ will spill over and raise $w$ as well. The strength of this link, or effectively the slope of $L$, will depend on the relative labor supply elasticities, $\eta^{*}+\epsilon$ and $\eta+\epsilon$ adjusted with $\epsilon$ to reflect the tie between the two countries via the offshoring relationship.

Interestingly, a reduction in the offshoring cost has two effects on schedule $L$. First it has a negative labor demand impact on the intensive margin as each unit of a task offshored can be performed by fewer workers. Second there is a positive impact on the extensive margin of offshoring in that the measure or proportion of tasks offshored goes up, i.e., I goes up, which means that the marginal task performed has a higher degree of complexity. As can be seen from equation (4), the former effect dominates when $1-\epsilon>0$, which leads to a reduction in the offshoring cost to shift the $L$ schedule up, in which case 
the value of $w$ compatible with a given $w^{*}$ will now be lower (Figure 1). Obviously the shift will be in the reverse direction when $1-\epsilon<0$.

To close the model, we note that the price $\left(p_{x}\right)$ equal unit cost relation in the production of $x^{*}$ is given by:

$$
w^{*}(1-I)+w \beta \int_{0}^{I} t(i) d i=p_{x}
$$

Denote

$$
\theta^{*}=\frac{w^{*}(1-I)}{p_{x}}
$$

as the developed country share of the total labor cost in the production of $x^{*}$, we have, upon totally differentiating (5),

$$
\theta^{*} \hat{w}^{*}+\left(1-\theta^{*}\right) \hat{w}=-\left(1-\theta^{*}\right) \hat{\beta}
$$

This zero profit condition is depicted graphically as schedule $\pi$ in Figure 1. From (6), any increases in $w^{*}$ must lead to a reduction in $w$, all else equal. The strength of this link is determined by the wage cost share $\theta^{*}$. Furthermore, the productivity impact of a reduction in offshoring cost applies unambiguously here as a reduction in $\beta$ shifts the $\pi$ schedule upwards (Figure 1).

The equilibrium impact of a reduction in offshoring cost on $w^{*}$ and $w$ thus depend on the relative strength of the three aforementioned effects: (i) the intensive margin labor demand impact, (ii) the marginal task complexity or extensive margin impact, and (iii) the productivity impact. Making use of (4) and (6), the balance of these three effects are summarized here:

$$
\frac{\hat{w}^{*}}{\hat{\beta}}=-\frac{\left(1-\theta^{*}\right)(1+\eta)}{\theta^{*}(\eta+\epsilon)+\left(1-\theta^{*}\right)\left(\eta^{*}+\epsilon\right)}<0, \quad \frac{\hat{w}}{\hat{\beta}}=-\frac{\epsilon+\eta^{*}-\theta^{*}\left(1+\eta^{*}\right)}{\theta^{*}(\eta+\epsilon)+\left(1-\theta^{*}\right)\left(\eta^{*}+\epsilon\right)} .
$$

Furthermore, since

$$
\frac{\hat{\rho}}{\hat{\beta}}=\frac{\hat{w}^{*}}{\hat{\beta}}-\frac{\hat{w}}{\hat{\beta}}-1
$$

substituting the solutions we have obtained for $\hat{w}^{*} / \hat{\beta}$ and $\hat{w} / \hat{\beta}$, we have

$$
\frac{\hat{\rho}}{\hat{\beta}}=\frac{-(1+\eta)}{(\eta+\epsilon) \theta^{*}+\left(\eta^{*}+\epsilon\right)\left(1-\theta^{*}\right)}<0
$$


Since $t(I)=\rho$, we have $d I / d \beta=(1 / t(I))(d \rho / d \beta)<0$. Thus the range or proportion of tasks offshored and the complexity of the marginal task offshored increases with a reduction in $\beta$.

Proposition 1 A parametric reduction in the cost of offshoring

- always increases the range of tasks offshored, I,

- always increases the developed country wage, $w^{*}$.

- decreases (increases) the developing country wage $w$ if and only if $\left(\epsilon+\eta^{*}\right) /\left(1+\eta^{*}\right)<$ $(>) \theta^{*}$

These fundamentally unequal wage responses to the same cost saving technological improvement are only possible when the intensive margin labor demand impact exceeds the task complexity impact: $1>\epsilon$. If this is indeed the case, then an asymmetric wage response to a reduction in $\beta$ is all the more likely when the developed country labor supply $L^{*}\left(w^{*}\right)$ is sufficiently inelastic $\left(\eta^{*}\right.$ is small). This is shown in Figure 1, where the upward shift of the $L$ schedule more than completely erases any potential developing country wage gains through the shift in $\pi$. At the limit, where the developed country labor market is fully inelastic $\left(\eta^{*}=0\right)$, a reduction in the cost of offshoring raises $w^{*}$ but decreases $w$ if and only if the task complexity impact $\epsilon$ is less than the developed country wage share $\theta^{*}$.

Defining the demand for labor from the offshoring sector faced by the developing country as $L_{x}^{d}=\lambda L^{*}\left(w^{*}\right)$ and further denoting the total elasticity of $L_{x}^{d}$ with respect to $w$, factoring in its impact on $w^{*}$, as $\xi^{d}$,we show in the appendix that $\xi^{d}=\left(\epsilon+\eta^{*}\left(1-\theta^{*}\right)\right) / \theta^{*}$ and the condition for a parametric reduction in the cost of offshoring to reduce the developing country wage, $w$ can be equivalently written as $\xi^{d}<1$ (while the condition for the developing country wage to rise as a result of the offshoring cost reduction is $\left.\xi^{d}>1\right)$. 
If we define developed and developing country welfare $\left(W^{*}\right.$ and $\left.W\right)$ simply as the total value added or income generated in the two sectors:

$$
W^{*}=F^{*}\left(L_{y}^{*}\right)+w^{*} x^{*}(1-I), \quad W=F\left(L_{y}\right)+w x^{*} \beta \int_{0}^{I} t(i) d i
$$

then an immediate corollary of proposition 1, replacing wage with welfare, applies immediately under the exact same set of conditions.

As indicated above, while $1-\epsilon>0$ or $\epsilon<1$ ensures an upward shift in the $L$ schedule, for this upward shift to be greater than the upward shift in the $\pi$ curve we need the more stringent condition $\left(\epsilon+\eta^{*}\right) /\left(1+\eta^{*}\right)<\theta^{*}$, or equivalently $\epsilon<\theta^{*}-\left(1-\theta^{*}\right) \eta^{*}<1$. This is more likely to happen when the developed country's share in the cost is high and/or the labor supply to the $x^{*}$ sector is highly elastic. In what follows, we will demonstrate in a series of numerical simulations that these intuitions are indeed borne out.

\section{Simulations}

In this section, we introduce specific functional forms in order to demonstrate the diverse ways in which the cost of offshoring can impact wages in developing countries as summarized in Proposition 1. Specifically, let

$$
t(i) \equiv \frac{1}{1-\sigma i}, \quad \sigma>0
$$

and furthermore, let

$$
L^{*}\left(w^{*}\right)=\ell^{*}\left(w^{*}\right)^{\phi}, \quad L(w)=\ell w^{\phi}, \ell^{*}, \ell>0, \quad \phi>0 .
$$

The cost of offshoring $t(i)$ is strictly increasing and convex in the complexity of the task. At given task complexity $i$, a sector with a high parameter $\sigma$ faces a higher increase in offshoring cost as task complexity increases. To focus on the role of the cost of offshoring, we make simple assumptions on the labor supply to the $x$ sector in the two countries, at constant elasticity $\phi>0$. 
Using (8), the elasticity $\epsilon$ and the wage share $\theta^{*}$ can be expressed succinctly as:

$$
\epsilon=\frac{1}{\log (\rho)}+\frac{1}{\rho(\sigma-1)+1}, \quad \theta^{*}=\frac{\rho(\sigma-1)+1}{\rho(\sigma-1)+1+\log (\rho)} .
$$

As shown, $\epsilon$ and $\theta^{*}$ are completely determined by the parameter $\sigma$, and the variable $\rho$. All else equal, a higher $\sigma$ translates to (i) a reduction in the elasticity of offshored employment intensity with respect to the relative wage cost, $\epsilon$, and (ii) an increase in the developed country wage cost share $\theta^{*}$ as offshoring higher complexity task to the developing country is costly at high $\sigma$. Thus, while a priori the inequality displayed in Proposition 1 may or may not be satisfied, it is conceivable that the developing country wage will be adversely affected by a parametric reduction in offshoring $\operatorname{cost} \beta$ in industries where $\sigma$ is sufficiently high.

With the addition of (12), the two equations (3) and (5) can be solved numerically. ${ }^{11}$ Figure 2 plots the equilibrium developing country wage (in log scale) as a function of the cost of offshoring $\beta$ for successively increasing values of $\sigma^{\prime}$ s. ${ }^{12}$ As shown, starting from $\sigma$ sufficiently small (at $\sigma=1$ where $\epsilon$ is relatively high, all else equal), the developing country wage response to a reduction in $\beta$ is monotonically positive. As $\sigma$ rises (at $\sigma=5,10)$, the developing country wage response exhibits an inverted U-shape. Finally, when $\sigma$ is sufficiently high (at $\sigma=20$ and thus where $\epsilon$ is sufficiently low), the developing country wage decreases in response to a reduction in the cost of offshoring. These results are consistent with the findings reported in Proposition 1.

The basic messages are two-fold. First, the developing country wage impact of a parametric reduction in the cost of offshoring depends on how steeply the task-specific offshoring cost is rising in task complexity, where the steepness of this relationship and the responsiveness of the proportion of tasks offshored to a change in the effective relative wage, $\frac{w^{*}}{w \beta}$ are inversely related. Furthermore, the developing country wage impact of a reduction in the cost of offshoring can change as increasingly complex tasks are offshored.

\footnotetext{
${ }^{11}$ Specifically, (3) and (12) jointly imply $\lambda^{-1 / \phi}=\rho \beta$. The implicit solution of this equilibrium relationship, using (2), gives the equilibrium relative wage cost $\rho$. Substituting $\rho$ into (5) gives $w=p_{x} \sigma /(\beta(\rho(\sigma-1)+1)+\log (\rho))$.

${ }^{12}$ In addition to the values of $\sigma$ indicated, we further more make the following assumptions: $\phi=1$, $\beta=2, p_{x}=1$.
} 
Indeed, as shown in Figure 2, for example, the developing country wage exhibits an inverted U-shaped relationship with $\beta$ (for $\sigma=5$; 10), indicating that the developing country wage first rises, and then eventually falls with successive parametric reductions in the cost of offshoring.

\section{The Impact of Parametric Offshoring Cost Reduc- tion on Global Welfare}

As mentioned earlier, national welfare rises (falls) with a reduction in $\beta$ as wage rises (falls). When both $w$ and $w^{*}$ rise with a reduction in $\beta$ it is quite clear that the joint welfare of the developed country and the developing country, which we will call global welfare from now on, will rise. However, there is also the case where $w$ falls and $w^{*}$ rises with a fall in $\beta$. In that case what happens to global welfare? This question is important since it answers the question whether offshoring would still benefit the developed country even if it had to compensate the developing country for the loss in its welfare.

We can write global welfare as the sum of the developed and developing country welfares as follows.

$$
W^{G}=F_{y}^{*}\left(L_{y}^{*}\right)+w^{*}\left(\overline{L^{*}}-L_{y}^{*}\right)+F_{y}\left(L_{y}\right)+w\left(\bar{L}-L_{y}\right) .
$$

Totally differentiating with respect to $\beta$ and noting that $F_{y}^{*}\left(L_{y}^{*}\right)=w^{*}$ and $F_{y}\left(L_{y}\right)=w$ we have

$$
\frac{d W^{G}}{d \beta}=\left(\bar{L}^{*}-L_{y}^{*}\right) \frac{d w^{*}}{d \beta}+\left(\bar{L}-L_{y}\right) \frac{d w}{d \beta}
$$

This, in turn, can be written as

$$
\begin{aligned}
\frac{d W^{G}}{d \beta} & =\left(\bar{L}^{*}-L_{y}^{*}\right)\left[1+\left(\frac{1-\theta^{*}}{\theta^{*}}\right)\left(\frac{\hat{w} / \hat{\beta}}{\hat{w}^{*} / \hat{\beta}}\right)\right] \frac{d w^{*}}{d \beta} \\
& =L_{x}^{*}\left[\frac{\eta \theta^{*}+\epsilon+\eta^{*}\left(1-\theta^{*}\right)}{(1+\eta) \theta^{*}}\right] \frac{d w^{*}}{d \beta}<0
\end{aligned}
$$

Therefore, we get the following proposition. 
Proposition 2 Global welfare always increases with a parametric reduction in offshoring costs (a reduction in $\beta$ ).

\section{$5 \quad$ Policy Implications and Optimal Policy}

As the offshoring decisions in the developed country directly affect labor demand in the developing country's offshoring sector, the policies we look at directly target workers in that sector. In particular, we analyze the effects of a sector-specific wage tax and minimum wage policy in the developing nation. We also derive optimal levels of these policies in our setting. Here it would be in order to make a clarification. As discussed earlier, offshoring is a form of trade. In trying to fix a directly trade related distortion, the first-best line of attack is trade policy. However, noting that these services (performing of offshored tasks) are exclusively produced for export and viewing workers in the developing country's offshoring sector as exporters of these services, it is easily seen that there is no difference effectively between an export tax and a wage tax. However, to trading partners using trade policy disguised in the form of a wage tax or a minimum wage might be less objectionable than the direct use of trade policy to shift real income.

\subsection{Wage Tax}

We first consider here an exogenous tax, $\tau$ on the wage in the offshoring sector in the developing country. In equilibrium, under perfect intersectoral labor mobility the wage paid by the employers in sector $y$ would be $w(1-\tau)$. Therefore, in the presence of this wage tax we modify the derivation of schedule $L$ slightly. We replace $L(w)=\bar{L}-L_{y}(w)$ with $L(w(1-\tau))=\bar{L}-L_{y}(w(1-\tau))$. Nowhere else in the equation for schedule $L$ or even schedule $\pi$ does $\tau$ enter. It is easy to see that this means that in Figure 1 , the schedule $L$ with a positive $\tau$ will lie to the right of the schedule $L$ with $\tau=0$. Any further increase in $\tau$ will shift schedule $L$ further to the right. Schedule $\pi$ remains unchanged. This means that equilibrium $w$ increases with $\tau$. 
We are going to assume that the tax revenue collected in the developing country will be distributed lump sum equally within the population. As a result, aggregate welfare in the developing country is given by

$$
W=F_{y}\left(\bar{L}-L_{x}\right)+w L_{x} .
$$

Note that the post-tax wage bill received by workers in the offshoring sector in the developing country is $w(1-\tau) L_{x}$ and the tax revenue collected $w \tau L_{x}$ is distributed by the government equally to the population. Thus $w L_{x}$ is the after-tax wage bill received by workers in the offshoring sector plus the government's tax revenue. As mentioned above, in equilibrium, workers should be indifferent between working in sector $y$ and sector $x$, which means employers in the $y$ sector will be paying wage $w(1-\tau)$. Using $d L_{x}^{d}\left(w, w^{*}, \beta\right) / d w=\partial L_{x}^{d} / \partial w+\left(\partial L_{x}^{d} / \partial w^{*}\right)\left(d w^{*} / d w\right)$, where $\partial w^{*} / \partial w$ is a movement along the existing schedule $\pi$, we have

$$
\frac{d W}{d \tau}=-F_{y} \frac{d L_{x}^{d}}{d w} \cdot \frac{d w}{d \tau}+L_{x} \frac{d w}{d \tau}+w \frac{d L_{x}^{d}}{d w} \cdot \frac{d w}{d \tau}
$$

Substituting $F_{y}=w(1-\tau)$, we have

$$
\frac{d W}{d \tau}=\left[1-\tau \xi^{d}\right] L_{x} \frac{d w}{d \tau} .
$$

At $\tau=0$, clearly $d W / d \tau=L_{x}(d w / d \tau)>0$. Thus starting from a zero wage tax, a small increase in wage tax increases welfare, indicating that the the optimal wage tax is positive. Since $0 \leq \tau<1$, when $\xi^{d}<1$ we have $\left[1-\tau \xi^{d}\right] L_{x}(d w / d \tau)>0$. In other words, when $\xi^{d}<1$,i.e., $\left(\epsilon+\eta^{*}\right) /\left(1+\eta^{*}\right)<\theta^{*}, d W / d \tau>0$. In fact, $d W / d \tau>0$ when $\xi^{d}<1 / \tau$. This means that for a small enough $\xi^{d}$ and/or $\tau$ there will be an increase in welfare from raising $\tau$.

The first order condition to obtain the optimal wage tax in (16) is $d W / d \tau=$ $\left[1-\tau \xi^{d}\right] L_{x}(d w / d \tau)=0$, which gives us the following optimal wage tax:

$$
\tau^{o}=\frac{1}{\xi^{d}}
$$

Note that this solution will obtain as long as there is an interior solution to maximizing welfare with respect the wage tax rate. Since $0 \leq \tau^{o}<1$, the existence of an interior 
solution to this optimal tax problem means that at that tax $\xi^{d}>1$,i.e., $\left(\epsilon+\eta^{*}\right)\left(1+\eta^{*}\right)>$ $\theta^{*}$. Note that these elasticities are endogenous variables in our model and, except under rare cases, are not exogenous parameters. This means, for instance, it is possible that $\xi^{d}<1$ at $\tau=0$ but rises with $w$ (which rises with $\tau$ ) so that at $\tau^{o}$ we have $\xi^{d}>1$.

We need to understand here the intuition behind a positive optimal wage tax. As a seller of services or tasks, the developing country in our model has monopoly power in the world market. Just as a monopoly firm in the market sets a markup over its cost in inverse relation to its elasticity of demand, the government of this country also levies a tax on wages received in this sector, which is inversely related to the labor demand elasticity. The reason in both cases is to use market power to restrict output to get a better price for what the country or the firm is selling. A higher elasticity would mean that a wage tax would lead to a larger distortion in the domestic labor market, while it would bring about a terms of trade benefit. As a result when this elasticity is low the wage tax rate is high.

Since we have shown earlier that $\xi^{d}=\left(\epsilon+\eta^{*}\left(1-\theta^{*}\right)\right) / \theta^{*}$, we can equivalently write the optimal wage tax formula as

$$
\tau^{o}=\frac{\theta^{*}}{\epsilon+\eta^{*}\left(1-\theta^{*}\right)}
$$

Intuitively, the higher is the developed country's wage share the greater is the scope for shifting real income away from the developed to the developing country. However, if the proportion of tasks offshored is highly responsive to the relative wage, a high wage tax in the developing country will greatly reduce the number of tasks offshored and also, therefore, will lead to a reduction in developing country employment in the offshoring sector. And finally, if the domestic labor supply faced by the offshoring sector in the developed country is very elastic, then an increase in the wage tax in the developing country will severely reduce the quantity of domestic labor supplied to the developed country's offshoring sector (from the rest of the economy) and in turn, by complementarity, reduce the demand for labor in the developing country's offshoring sector. The reason is that the induced increase in the developing country's gross-of-tax wage will reduce developed 
country wage by the zero profit condition.

We next look at how welfare changes with a change in $\beta$, first in the presence of an exogenous wage tax and then in the presence of an optimal wage tax. In the presence of an exogenous wage tax we have

$$
\frac{d W}{d \beta}=\left[1-\tau \xi^{d}\right] L_{x} \frac{d w}{d \beta}+w\left[\frac{d L_{x}^{d}}{d \beta}\right]_{d w=0} .
$$

When $\xi^{d}<1$,we have $\left[1-\tau \xi^{d}\right] L_{x}(d w / d \beta)>0$. We also show in the appendix that when $\xi^{d}<1$, we have $\left[d L_{x}^{d} / d \beta\right]_{d w=0}>0$. Thus, welfare falls with a parametric reduction in offshoring costs in the presence of an exogenous tariff as long as $\xi^{d}<1$.

In the presence of an optimal wage tax, which adjusts optimally to any changes in $\beta$, we have

$$
\frac{d W}{d \beta}=w\left[\frac{d L_{x}^{d}}{d \beta}\right]_{d w=0} .
$$

In the appendix we show that $\left[d L_{x}^{d} / d \beta\right]_{d w=0}<0$ when $\xi^{d}>1$ (always true at an interior optimal tax rate). Thus, if a wage tax can be optimally set, then $d W / d \beta<0$. The reason is that the terms of trade loss or the wage rate decline as a result of a parametric reduction in the offshoring costs is neutralized by an offsetting change in the optimal wage tax rate. Thus we have the following proposition.

Proposition 3 (A) Starting from a zero wage tax, a small increase in this tax increases welfare.

(B) The optimal wage tax is given by $\tau^{o}=1 / \xi^{d}$, i.e., the optimal wage tax rate equals the inverse of the total labor demand elasticity in the offshoring sector of the developing country.

(C) While at an exogenously given wage tax a parametric reduction in the offshoring cost may increase or decrease developing country welfare, when the wage tax is always optimally set this offshoring cost reduction will unambiguously increase welfare. 


\subsection{The Effect of a Parametric Decline in the Offshoring Cost on the Optimal Tax}

While we have established that the presence of an optimal tax rules out welfare reduction for the developing nation, we have not yet thrown light on how the optimal tax behaves with respect to changes in $\beta$. This is an interesting question in its own merit, but it is also important in order to understand effects on the developing nation wage $w$, which is a function of both $\beta$ and $\tau$. In the appendix, we show that if labor demand curve in the offshoring sector of the developing nation is linear or concave, then the optimal tax must rise with a decline in $\beta$. It will also rise if the demand function is not too convex. The intuition is the following. Given $\beta$, the effect of change of $w$ on the effective wage $w \beta$ facing the foreign firm (i.e., $d(w \beta)=\beta d w)$ is scaled by $\beta$. Consequently, at a lower $\beta$, a given wage increase reduces labor demand in the offshoring sector to a lesser degree. In addition, at a lower $\beta$, labor demand in the offshoring sector is higher at a given wage $w$. Both of these effects elicit a smaller percentage response in labor demand when $w$ rises by one percent. The developing nation's government sees this as an opportunity to raise the tax (at the margin) to further raise $w$, because it now faces a lower marginal cost in terms of reduced employment.

If the optimal tax rises, then $w$ must rise with a decline in $\beta$. This is because of the direct effect of $\beta$ on $w$ at a given tax rate (at the optimum, demand is elastic), and also because of the indirect effect through a rise in the optimal tax, which will push the wage up (because $d w / d \tau>0)$.

Using the notations developed in Section 3, the size of the optimal tax, and the associated wage in the offshoring sector of the developed and the developing country can be simulated. ${ }^{13}$ In Figures $3 \mathrm{a}$ and $3 \mathrm{~b}$, we display the relationships between the $w$ and $\beta$, and $w^{*}$ and $\beta$, respectively, under the optimal wage tax. As shown, once an optimal wage tax is in place, any adverse impact that a reduction in offshoring cost can have on

\footnotetext{
${ }^{13}$ Specifically, using (12) upon replacing $w$ with $w(1-\tau)$ in the presence of a wage tax, the relationship between $\rho$ and the wage tax is given implicitly by $\tau=\rho \beta \lambda^{-\phi}$, where $\lambda$ itself is a function of $\rho$. In addition, by the optimal wage tax formula in $(17), \tau=\theta^{*} /\left(\epsilon+\eta\left(1-\theta^{*}\right)\right)$ where the right hand side is once again a function of $\rho$. The optimal tax simultaneously solves these two equations in two unknowns $\tau$ and $\rho$.
} 
the developing country wage no longer applies. Indeed, the wage in the offshoring sector in both countries are monotonically increasing with respect to successive parametric reductions in the offshoring cost. ${ }^{14}$

\subsection{Minimum Wage}

In place of the wage tax, let us now consider an exogenous binding minimum wage, $\bar{w}$ in the offshoring sector of the developing country. Whoever cannot be employed in this sector at this minimum wage finds employment in the other sector at a lower wage. Thus, wages differ between the sectors (and there are no tax revenues). Hence, a higher minimum wage results in a higher inequality between workers in the two sectors. However, with the wage tax we saw that the net-of-tax wage was equal between the sectors and there was no such inequality generated. Despite the inequality arising out of the sectorspecific minimum wage, it might be worth considering it for good reasons. For example, a discriminatory tax on workers in a particular sector could be unpopular, but a wage floor on workers working for foreign employers or outsourcers might not be since it would be viewed as something that narrows the gap with the employees of these firms in the developed country. As argued in the introduction, this might also be faciliated by the activism of labor advocacy groups and antisweat shop campaigns. Aggregate welfare in the developing country in the presence of this minimum wage is then given by

$$
W=F_{y}\left(\bar{L}-L_{x}\right)+\bar{w} L_{x}
$$

We then have

$$
\frac{d W}{d \beta}=\left(\bar{w}-F_{y}\right)\left[\frac{d L_{x}^{d}}{d \beta}\right]_{d w=0} \lessgtr 0 \text { as } \xi^{d} \gtrless 1
$$

since $F_{y}$ is the wage in sector $y$ in this country and is below the binding minimum wage, $\bar{w}$ in the sector $x$. Thus when the demand for labor in the offshoring sector is elastic, a parametric fall in the offshoring cost leads to an increase in the developing country's

\footnotetext{
${ }^{14}$ It is interesting that our simulations show that the developing country wage and even the developed country wage always rise with reductions in $\beta$ even in the presence of wage taxation in the developing country. We know that $\tau^{0}$ rises with reductions in $\beta$, unless labor demand is too convex. Since $\xi^{d}$ is increasing in $w \beta$ when labor demand is not too convex, $w \beta$ will fall and from the zero-profit condition $w^{*}$ will rise.
} 
aggregate welfare but in the presence of an inelastic demand this parametric offshoring cost reduction leads to a decline in a aggregate welfare in the developing country. We have shown in the appendix that $\left[d L_{x}^{d} / d \beta\right]_{d w=0} \lessgtr 0$ as $\xi^{d} \gtrless 1$.

The formula for the optimal minimum wage in the offshoring sector follows the formula for the optimal tax as follows.

$$
\frac{\bar{w}^{o}-F_{y}}{\bar{w}^{o}}=\frac{1}{\xi^{d}}
$$

Thus the wedge between the wages in the two sectors is the same under both the optimal wage tax and the optimal minimum wage in the offshoring sector. Effectively, the optimal minimum wage will equal the equilibrium developing country wage corresponding to the optimal wage tax. As shown by the simulations in Figure 3a, the optimal minimum wage will rise with a reduction in $\beta$.

What happens when the minimum wage is economywide? Then there is unemployment and in the presence of an exogenous given minimum wage, $\bar{w}$ we have

$$
\frac{d W}{d \beta}=\bar{w}\left[\frac{d L_{x}^{d}}{d \beta}\right]_{d w=0} \lessgtr 0 \text { as } \xi^{d} \gtrless 1 .
$$

The welfare effect of an offshoring cost reduction does not change qualitatively.

Now what is the optimal economywide minimum wage? Denoting the economy's total employment by $N$, we now have

$$
\frac{d W}{d \bar{w}}=\left[s_{x}-s_{x} \xi^{d}-\left(1-s_{x}\right) \xi_{y}^{d}\right] N
$$

where $\xi_{y}^{d}$ is the elasticity of labor demand in the sector $y$ and $s_{x}=L_{x} / N$. Thus if the employment weighted average labor demand elasticity in the economy is less than $s_{x}$, i.e., if labor demand on average is quite inelastic at the equilibrium with no government intervention then there will be a welfare gain from setting a minimum wage at least slightly above that equilibrium wage. However, if the share of employment in the offshoring sector is low and labor demand is fairly elastic on average, the optimal policy of the government will be to not set an economywide minimum wage. In the first case (highly inelastic labor demand and/or high employment share of the $x$ sector), if an 
interior optimum economywide binding minimum wage exists it will the one where the following condition holds

$$
s_{x}=s_{x} \xi^{d}+\left(1-s_{x}\right) \xi_{y}^{d}
$$

It is important to see that with a binding general minimum wage there will be some unemployment. Also, it is easy to see that this minimum wage will be inferior to the sector-specific minimum wage analyzed earlier. ${ }^{15}$

\section{Discussion and Conclusion}

In this paper, we have studied certain channels through which a reduction in the cost of offshoring can affect wages in a developing country. In addition to a positive "productivity effect," these channels include an increase in the demand for developing country labor as a result of an increasing range of tasks offshored but a decline in labor demand due to a lower labor requirement per unit task. Since all the effects through these various channels are not in the same direction, we get a variety of results, depending on parameter values, showing that the impact in the developing country of a reduction in the cost of offshoring need not always be a wage increase. In fact, a wage reducing impact is quite possible. We show the following possibilties in response to parametric reductions in the offshoring cost: (1) wages monotonically improve, (2) wages monotonically decline, and (3) wages exhibit an inverted U.

Our analysis shows that while improvements in offshoring technology must benefit the developed nation and the two nations (developed and developing) taken together, its effect on the developing nation is ambiguous. If the labor saving effect of technological improvement (effectively a terms of trade loss) dominates, the developing nation may suffer a welfare loss. This outcome arises when the labor demand in the offshoring sector is inelastic. This surprising welfare effect is akin to Bhagwati's (1958) immiserizing growth paradox, but takes place in a very different context and under considerably less

\footnotetext{
${ }^{15}$ Any sector-specific minimum wage of the same level as the optimal general minimum wage will result in a higher developing country welfare (as output in sector $x$ will not change but the output in sector $y$ will be higher). In turn, the optimal sector-specific minimum wage wil result in at least as much, if not even higher, welfare.
} 
restrictive conditions. We extend the analysis to the case where the developing nation can tax wages in the offshoring sector. If this tax is exogenously given, the welfare paradox cannot be ruled out. However, if the tax is set at an unilaterally optimal level, the equilibrium must occur on the elastic range of the labor demand curve. ${ }^{16}$ We get similar results using an optimal minimum wage.

It is important to note that in our model both the developed and developing countries are small in the world market for final goods market. However, if these countries are treated as large instead, a reduction in the offshoring cost will increase the relative world supply of the good whose production allows for offshoring. As a result, it's relative price will go down, in turn acting as a separate channel through which wages in both countries will be impacted.

There are a few possible extensions that come to mind. One possibility is bringing in multiple developing nations to which firms in the developed country offshore. ${ }^{17}$ When setting optimal policies these developing countries will compete with each other. With symmetric developing countries, we expect that due to the competition effect the equilibrium wage tax rate will be lower than what is optimum for these countries together. If these countries are setting their minimum wage then the equilibrium might be that of no intervention at all as otherwise a country can lower its binding minimum wage below those of other countries to become the recipient of all the offshoring.

\section{Appendix}

A. To prove: The condition for a parametric reduction in the cost of offshoring to reduce the developing country wage, $w$ can be equivalently written as $\xi^{d}<1$ (while the condition for the developing country wage to rise as a result of the offshoring cost reduction is $\left.\xi^{d}>1\right)$.

Proof: We can write the demand for labor in the developing country from the offshoring industry as $L_{x}^{d}=\beta .(\lambda / \beta) . L^{*}\left(w^{*}\right)$. Assuming no change in $\beta$, the total elasticity

\footnotetext{
${ }^{16}$ See Bhagwati (1968) for an analogous result in a somewhat different context of export-biased growth.

${ }^{17}$ An example of a paper on strategic sourcing to multiple countries is Sly and Soderbery (2014).
} 
of $L_{x}^{d}$ with respect to $w$, factoring in its impact on $w^{*}$, can be written as $\xi^{d}=-\frac{d \ln L_{x}^{d}}{d \ln w}=$ $-\left(\frac{d \ln (\lambda / \beta)}{d \ln \rho} \cdot \frac{d \ln \rho}{d \ln w}+\frac{d \ln L^{*}\left(w^{*}\right)}{d \ln w^{*}} \cdot \frac{d \ln w^{*}}{d \ln w}\right)=-\epsilon\left(\frac{d \ln w^{*}}{d \ln w}-1\right)-\eta^{*} \frac{d \ln w^{*}}{d \ln w}$. With $d \ln \beta=0$, we have, from the zero profit condition, $\theta^{*} d \ln w^{*}+\left(1-\theta^{*}\right) d \ln w=0 \Rightarrow \frac{d \ln w^{*}}{d \ln w}=-\left(1-\theta^{*}\right) / \theta^{*}$. Substituting this, we now have $\xi^{d}=-\epsilon\left[-\left(\left(1-\theta^{*}\right) / \theta^{*}\right)-1\right]+\eta^{*}\left(1-\theta^{*}\right) / \theta^{*}=\left(\epsilon+\eta^{*}(1-\right.$ $\left.\left.\theta^{*}\right)\right) / \theta^{*}$. Our condition in proposition 1 can be written as $\left(\epsilon+\eta^{*}\right) /\left(1+\eta^{*}\right) \lessgtr \theta^{*} \Longleftrightarrow$ $\epsilon+\eta^{*} \lessgtr \theta^{*}\left(1+\eta^{*}\right) \Longleftrightarrow \epsilon+\eta^{*}\left(1-\theta^{*}\right) \lessgtr \theta^{*} \Longleftrightarrow\left(\epsilon+\eta^{*}\left(1-\theta^{*}\right)\right) / \theta^{*} \lessgtr 1 \Leftrightarrow \xi^{d} \lessgtr 1$.

B. To prove: (i) $\left[\hat{L_{x}^{d}} / \hat{\beta}\right]_{d w=0} \lessgtr 0$ as $\xi^{d} \gtrless 1$. (ii) $\left[\hat{L_{x}^{d}} / \hat{\beta}\right]_{d w=0}<0$ at $\tau=\tau^{0}$.

Proof: $L_{x}^{d}=\beta .(\lambda / \beta) . L^{*}\left(w^{*}\right)$. At $d w=0$, we have $\hat{L}_{x}^{d}=\hat{\beta}+\epsilon\left(\hat{w}^{*}-\hat{\beta}\right)+\eta^{*} \hat{w}^{*}$. From the zero-profit condition equation (which is represented by the schedule $\pi$ in Figure 1), we have $\hat{w}^{*}=-\left(1-\theta^{*}\right) \hat{\beta} / \theta^{*}, \hat{w}^{*}-\hat{\beta}=-\hat{\beta} / \theta^{*}$ when $d w=0$. Thus we have $\left[\hat{L_{x}^{d} / \hat{\beta}}\right]_{d w=0}=$ $1-\frac{\epsilon}{\theta^{*}}-\eta^{*}\left(1-\theta^{*}\right) / \theta^{*}=1-\left[\left(\epsilon+\eta^{*}\left(1-\theta^{*}\right)\right) / \theta^{*}\right]=1-\xi^{d}$. Therefore, $\left[\hat{L_{x}^{d}} / \hat{\beta}\right]_{d w=0} \lessgtr 0$ as $\xi^{d} \gtrless 1$. Since $1-\xi^{d}<0$ at $\tau=\tau^{0}$, we have $\left[\hat{L_{x}^{d} / \hat{\beta}}\right]_{d w=0}<0$ at $\tau=\tau^{0}$.

C. To prove: Optimal tax rises with a fall in the offshoring cost parameter $\beta$ if labor demand in the offshoring sector of the developing nation is linear or concave.

Proof: Eq. (16) can be stated as $W_{\tau}(\tau, \beta)=0$. Using the second order condition of the optimal tax, $W_{\tau \tau}(\tau, \beta)<0$, we have: $\frac{d \tau}{d \beta}<0$ iff $\left[W_{\tau \beta}\right]_{\tau=\tau^{0}}<0$ iff $\left[d \xi^{d} / d \beta\right]_{\tau=\tau^{0}}>$ 0. Using Eqs.(1), (2) and (5), and noting from page 11 that $L_{x}^{d}=\lambda L^{*}\left(w^{*}\right)$, we can express labor demand in the offshoring sector as $L_{x}^{d}=\beta f(w \beta)$, where $f^{\prime}()<$.0 . This yields $\xi^{d}=-w \beta f^{\prime}(w \beta) / f(w \beta) \Rightarrow d \xi^{d} / d(w \beta)=\xi^{d}\left[\left(1+\xi^{d}\right) /(w \beta)+f^{\prime \prime} / f^{\prime}\right]>0$ if $f^{\prime \prime} \leq$ 0. Thus, if labor demand is linear or concave (i.e., $\left.f^{\prime \prime} \leq 0\right)$, then $\left[d \xi^{d} / d \beta\right]_{\tau=\tau^{0}}=$ $\left[d \xi^{d} / d(w \beta)\right][d(w \beta) / d \beta]_{\tau=\tau^{0}}>0$, because from Eq. (7) we know that $-\hat{w} / \hat{\beta}<1 \Rightarrow$ $[d(w \beta) / d \beta]_{\tau=\tau^{0}}>0$. Therefore, if $f^{\prime \prime} \leq 0$, then $d \tau / d \beta<0$.

\section{References}

[1] Bergin, P., R.C. Feenstra and G.H. Hanson (2011) "Volatility due to offshoring: Theory and evidence," Journal of International Economics 85(2), 163-173. 
[2] Bhagwati, J., (1958) "Immiserizing growth: A geometric note," Review of Economic Studies 25, 201-205.

[3] Bhagwati, J., (1968) "Distortions and immiserizing growth: A generalization," Review of Economic Studies 35, 481-85.

[4] Burstein, A. and J.Vogel (2010) "Globalization, technology and the skill premium: A quantitative analysis," NBER Working Paper No. 16459.

[5] Desai, M.A., Foley, C.F. and J.R. Hines (2005) "Foreign direct investment and the domestic capital stock," American Economic Review 95(2): 33-38.

[6] Feenstra, R.C. and G.H. Hanson (1996) "Foreign Investment, outsourcing and relative wages", in R.C. Feenstra et al. (eds). Political economy of trade policy: essays in honor of Jagdish Bhagwati: MIT Press, Cambridge, 89-127.

[7] Feenstra, R.C. and G.H. Hanson (1997) "Foreign direct investment and relative wages: Evidence from Mexico's maquiladoras," Journal of International Economics 42, 371-393.

[8] Grossman, G.M. and E. Rossi-Hansberg (2008) "Trading tasks: A simple theory of offshoring," American Economic Review 98(8): 1978-1997.

[9] Grossman, G. M. and E. Rossi-Hansberg (2012) "Task trade between similar countries." Econometrica 80(2), 593-629.

[10] Harrison, A.E. and M.S. McMillan (2011) "Outsourcing jobs? Multinationals and US employment," The Review of Economics and Statistics 93(3): 857-875.

[11] Harrison, A.E. and J. Scorse (2008) "Improving the Conditions of Workers? Minimum Wage Legislation and Anti-Sweatshop Activism," California Management Review 48(2), 144-160.

[12] Helpman, E. (1984) "A Simple Theory of Multinational Corporations," Journal of Political Economy 92(3), 451-71. 
[13] Hummels, D., Munch, J.R. and C. Xiang (2016) "Offshoring and Labor Markets," mimeo, Department of Economics, Purdue University.

[14] Krautheim, S. and T. Verdier (2015) "Offshoring with Endogenous NGO Activism," mimeo, PSE-Ecole des Ponts Paris Tech.

[15] Mankiw, N.G., and P. Swagel (2006) "The politics and economics of offshore outsourcing," Journal of Monetary Economics 53(5): 1027-1056.

[16] Mitra, D. and P. Ranjan (2010) "Offshoring and unemployment: The role of search frictions labor mobility," Journal of International Economics 81, 219-229.

[17] McMillan, M.S. (2009) "Production Offhsoring and Labor Markets: Recent Evidence and a CResearch Agenda," mimeo, Tufts University.

[18] Ranjan, P. (2013) "Offshoring, Unemployment, and Wages: The role of labor market institutions," Journal of International Economics 89 (1), 172-186.

[19] Sly, N. and A. Soderbery (2014) "Strategic Sourcing and Wage Bargaining," Journal of Development Economics 172-187. 


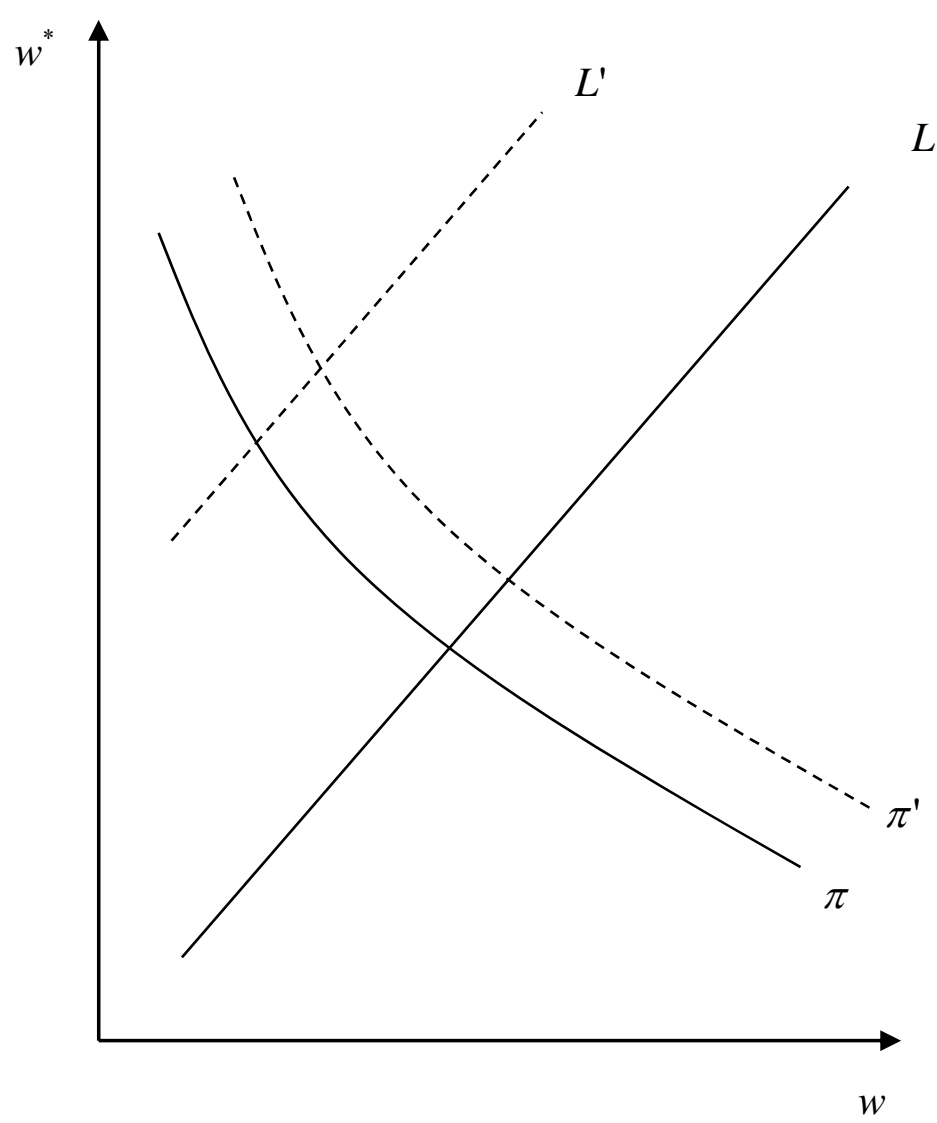

Figure 1. Unequal Gains from a Reduction in Offshoring Cost

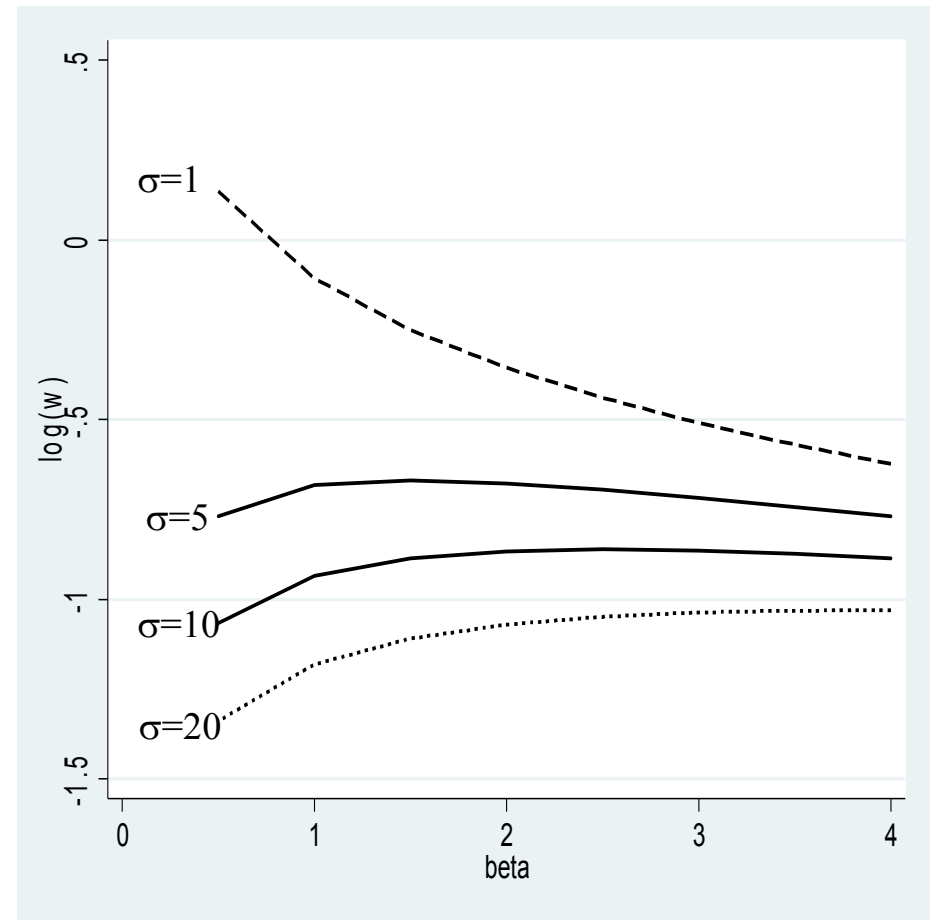

Figure 2. Developing Country Wage (w) Simulation: (Unregulated) 


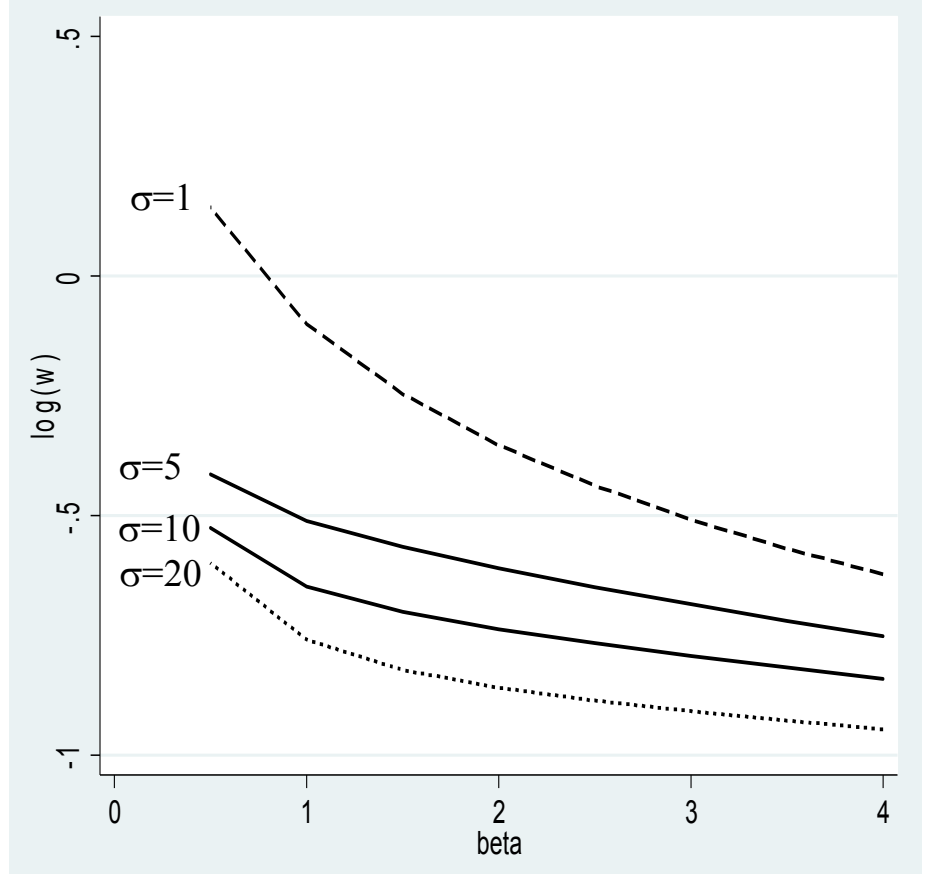

Figure 3a. Developing Country Wage (w) Simulation: (With Optimal Wage Tax)

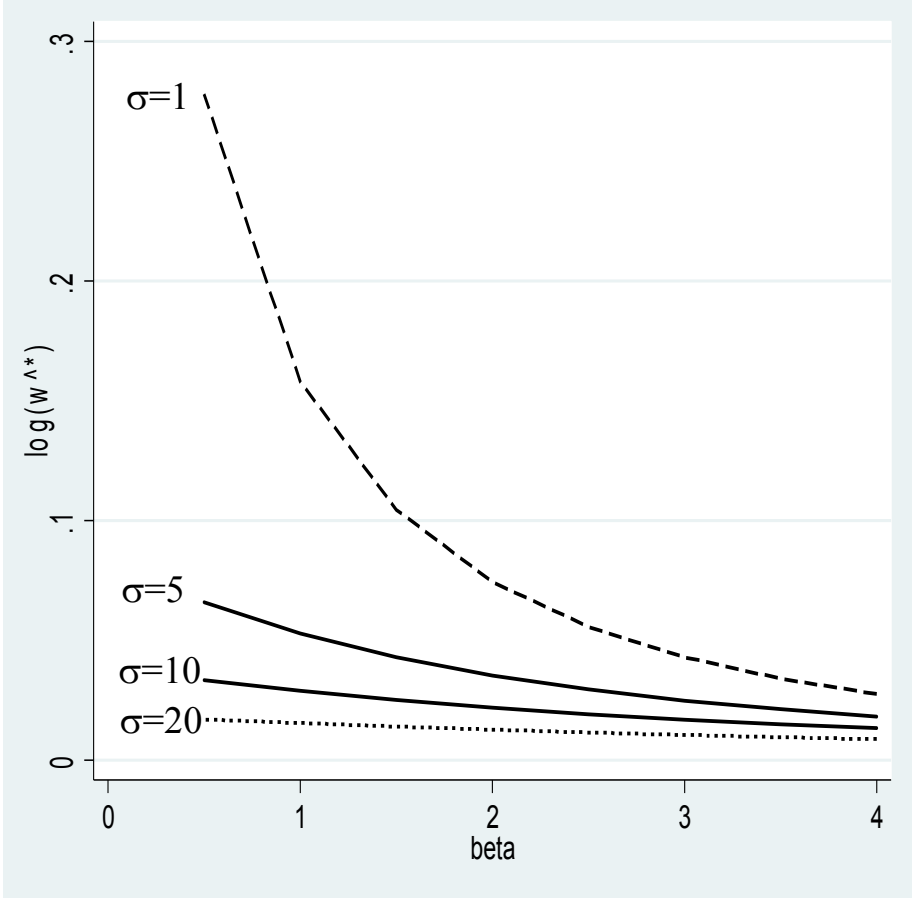

Figure 3b. Developed Country Wage ( $\left.w^{*}\right)$ Simulation: (With Optimal Wage Tax) 